\title{
A comparative trial of ice application versus EMLA cream in alleviation of pain during molluscum contagiosum removal by needle extirpation
}

\author{
Heena Gupta', Mrinal Gupta²
}

\author{
${ }^{1}$ Department of Anaesthesiology, Government Medical College, Jammu, India, ${ }^{2}$ Consultant Dermatologist, Treatwell Skin \\ CentreJammu, India
}

Corresponding author: Dr. Mrinal Gupta, E-mail: drmrinalgupta@yahoo.com

\begin{abstract}
Background: Molluscum contagiosum is a common viral disease seen among the pediatric age group. A wide variety of treatment modalities are available for their management but no therapy is universally effective. Destructive modalities like cryotherapy, extirpation and radiofrequency removal are commonly used but are painful. Aims and Objectives: To evaluate the efficacy of Eutectic Mixture of Local Anesthetics (EMLA) cream versus ice application in alleviation of pain during molluscum contagiosum removal by extirpation. Materials and Methods: In this prospective study, 30 patients underwent molluscum contagiosum removal by needle extirpation. In 15 patients, EMLA cream was applied prior to the procedure and in the other half, ice was applied directly before the removal. Pain was evaluated using a Visual Analog Scale and the differences were compared. Results: Statistically, there was a significant difference in pain control between EMLA cream group and ice application group $(p<0.05)$. The average pain score among patients where EMLA cream was applied was $7.6(\mathrm{SD}=0.81)$, whereas it was $5.1( \pm 0.9)$ in the ice group. Conclusion: In this study, use of ice application is helpful in reducing pain in comparison to EMLA cream during molluscum contagiosum needle extirpation.
\end{abstract}

Key words: Molluscum contagiosum; Extirpation; EMLA; Local anesthetics

\section{INTRODUCTION}

Molluscum contagiosum (MC) is a common viral infection caused by DNA Poxvirus. It has no other reservoir than humans and is transmitted directly by skin-to-skin contact or indirectly through fomites. It's a widely prevalent infection commonly affecting children, sexually active adults, and immunodeficient individuals [1]. A large number of treatments exist for treatment of $\mathrm{MC}$ which includes destructive therapies like curettage, cryotherapy, pricking with a sterile needle, electrodessication, photodynamic therapy and lasers. Other topical medications include salicylic acid, tretinoin, potassium hydroxide, trichloroacetic acid and imiquimod. However, no therapy is universally effective and most of these treatment modalities are not well tolerated as they are painful [2-4].
We carried out this study to evaluate the efficacy of Eutectic Mixture of Local Anesthetics (EMLA) cream versus ice application in alleviation of pain during molluscum contagiosum removal by extirpation.

\section{MATERIALS AND METHODS}

It was a prospective study carried out over a period of six months in which 30 patients (M:F 18:12), aged between 18-65 years were included. The patients were divided randomly in two groups. There were no statistical differences between the 2 groups in terms of baseline preoperative and operative characteristics. In 15 patients, EMLA cream was applied prior to the procedure and in the other half, ice was applied directly before the removal.For each patient, EMLA cream was

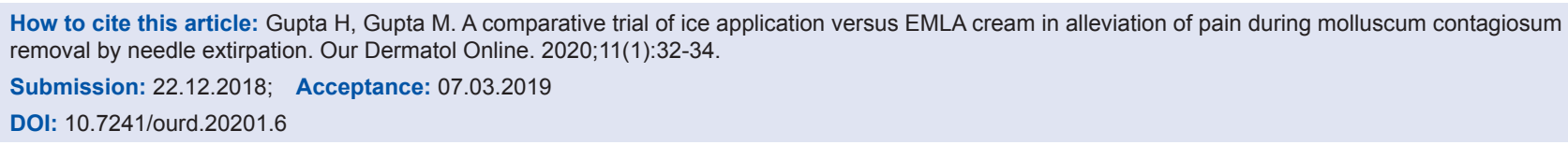


applied for 1 hour before the procedure. An ice cube was applied for few seconds ( $3-5$ seconds) immediately before the procedure. Pain was assessed by a numeric pain rating scale, where 0 indicated no pain and 10 the worst possible pain. Each patient was asked to self-report the pain intensity during the procedure. The molluscum were extirpated by using a $20 \mathrm{~g}$ needle.

\section{RESULTS}

The pain score was assessed immediately after the procedure. The mean pain score among all patients at the end of procedure was $6.2( \pm 0.9)$. The mean pain score was slightly higher among females $(6.4 \pm 0.4)$ as compared to males $(5.8 \pm 0.3)$. There was not much difference in pain score among patients aged $>50$ years $(5.8 \pm 0.6)$ and patients aged $<50$ years $(5.6 \pm 0.4)$. The mean pain score was also higher among patients with more than 5 molluscum lesions $(6.7 \pm 0.5)$ than among those with less than 5 lesions $(5.2 \pm 06)$. The average pain score among patients where EMLA cream was applied was $7.6( \pm 0.81)$, whereas it was $5.1( \pm 0.9)$ in the ice group $(p<0.05)$. During the study, no side effects were reported other than discomfort and pain from ice application noticed in 2 patients.

\section{DISCUSSION}

A large variety of treatment modalities have been used for molluscum but most of these involve destructive modalities which are painful so use of topical anesthesia becomes imperative for molluscum removal. Cooling of the skin is simple and cheap form of anesthesia. The exact mechanism of action of anesthesia by cooling is unknown, but several mechanisms, such as decreased nerve conduction, reduction in muscle spasms, prevention of edema after injury, a decrease in the release of pain-production substances locally, release of endorphins, and pain inhibition through inhibitory interneurons (pain gate), have been suggested [5-8]. These neural effects increase the patient's pain threshold and can diminish the need for pharmacologic interventions, such as narcotics or local anesthetics. Cold-induced analgesia has been shown to begin after the skin surface temperature lowers to $\sim 13.6^{\circ} \mathrm{C}$ and stops when temperature rises to more than $15.6^{\circ} \mathrm{C}$ [8].

The present study shows that the application of ice cube for few seconds prior to extirpation result in a significant pain reduction. Mahshidfar et al reported a significant reduction in pain with ice application before injection for wound site injections [9]. In our study, a change in the pain score was evident after the procedure with cooling. Although the absolute numbers were small, the changes were perceptible to the patients. Certainly, it is an inexpensive intervention and particularly ideal in resource-constrained facilities, such as those in developing communities.

\section{Limitations}

Our study had certain limitations. The small sample size of the study group was one of the limitations. Due to the nature of the procedure (i.e., the application of an ice pack over the procedure site), blinding of the patients and staff was not possible, therefore the subjects were only blindly randomized. The positive compression effect may also contribute to pain relief.

\section{CONCLUSION}

In the present study, the analgesic effect of cooling was assessed and found to be associated with less pain during removal of molluscum contagiosum. It can be used as a safe, cheap and effective modality of analgesia in dermatological procedures.

\section{Statement of Human and Animal Rights}

All procedures followed were in accordance with the ethical standards of the responsible committee on human experimentation (institutional and national) and with the Helsinki Declaration of 1975, as revised in 2008 .

\section{Statement of Informed Consent}

Informed consent was obtained from all patients for being included in the study.

\section{REFERENCES}

1. Gerlero P, Hernández-Martín Á. Update on the Treatment of molluscum Contagiosum in children. Actas Dermosifiliogr. 2018;109:408-15.

2. Go U, Nishimura-Yagi M, Miyata K, Mitsuishi T. Efficacy of combination therapies of topical $5 \%$ imiquimod and liquid nitrogen for penile molluscum contagiosum. J Dermatol. 2018;45:e268-9.

3. van der Wouden JC, Koning S, Katz KA. Interventions for nongenital molluscum contagiosum in persons without immune deficiency. JAMA Dermatol. 2018;154:203-4.

4. Sharquie KE, Noaimi AA, Ibrahim GA, Al-Husseiny AS. Topical therapy of molluscum contagiosum as a comparative therapeutic study using $15 \%$ phenol in lactic acid, 5\% tincture iodine and pricking alone. Our Dermatol Online. 2016;7:253-7.

5. Haynes JM. Randomized controlled trial of cryoanalgesia (ice 


\section{www.odermatol.com}

bag) to reduce pain associated with arterial puncture. Respir Care. 2015;60:1-5.

6. Watkins AA, Johnson TV, Shrewsberry AB. Ice packs reduce postoperative midline incision pain and narcotic use: a randomized controlled trial. J Am Coll Surg. 2014;219:511-7.

7. Fang L, Hung CH, Wu SL, Fang SH, Stocker J. The effects of cryotherapy in relieving postarthroscopy pain. J Clin Nurs. 2012;21:636-43.

8. Herrera E, Sandoval MC, Camargo DM, Salvini TF. Motor and sensory nerve conduction are affected differently by ice pack, ice massage, and cold water immersion. Phys Ther. 2010;90:551-9.
9. Mahshidfar B, CheraghiShevi S, Abbasi M, Kasnavieh MH, Rezai M, Zavereh M, et al. Ice reduces needle-stick pain associated with local anesthetic injection. Anesth Pain Med. 2016;6:e38293.

Copyright by Heena Gupta, et al. This is an open-access article distributed under the terms of the Creative Commons Attribution License, which permits unrestricted use, distribution, and reproduction in any medium, provided the original author and source are credited.

Source of Support: Nil, Conflict of Interest: None declared. 